\title{
Socio-Economic and Health Determinants of Rural Households Consent to Prepay for Their Health Care in N'Dali (North of Benin)
}

\author{
Soulé EL-HADJ IMOROU \\ Department of Sociology Anthropology, Faculty of Letters, Arts and Human Sciences, University of Parakou, Parakou, Benin \\ Email: imorousoule@yahoo.fr
}

How to cite this paper: EL-HADJ IMOROU, S. (2020). Socio-Economic and Health Determinants of Rural Households Consent to Prepay for Their Health Care in N'Dali (North of Benin). Open Journal of Social Sciences, 8, 348-360.

https://doi.org/10.4236/jss.2020.85024

Received: April 5, 2020

Accepted: May 23, 2020

Published: May 26, 2020

Copyright ( 2020 by author(s) and Scientific Research Publishing Inc. This work is licensed under the Creative Commons Attribution International License (CC BY 4.0). http://creativecommons.org/licenses/by/4.0/

\begin{abstract}
In order to know the importance of the pre-finance of the health care in a family, this article aims to analyze the real possibilities of households participating in the pre-financing of their health care. The data used for the analysis were collected from one hundred and twenty (120) households in N'Dali located in northern Benin. The results obtained show that more than half of rural households can agree to pay $7000 \mathrm{FCFA} /$ individual/year to pre-finance their health care. This willingness to pay households is influenced both by the characteristics specific to the respondents (age, educational level, number of children in the household, income level, etc.) as well as those specific to the local health services (prompt reception of patients, cleanliness of the health center and actual or periodic presence of a doctor in the health service).
\end{abstract}

\section{Keywords}

Willingness to Pay, Health Care, North Benin

\section{Introduction}

In the aftermath of their independence, African countries declared health as a right and introduced free healthcare for all. The health systems inherited from the colonial period were no longer adapted to the demographic distribution and the basic health needs of these countries. The 1980s therefore saw a profound reorganization of health systems in Africa, with strong decentralization and a strategy focused on prevention and primary health care (PHC). It was in Alma Ata in 1978 that the member countries of the World Health Organization officially gave the starting point for this new strategy. However, the latter quickly came up against the question of its funding. Over-indebted African countries 
could no longer finance their health services. The idea of funding healthcare services by recovering the costs of providing services to the sick appeared in the early 1980s and was officially launched by WHO in Bamako in September 1987 under the name of Initiative of Bamako. His basic premise was that the patient would be willing to pay a reasonable amount for his health care, provided he could find quality service and staff suited to his request.

In Benin, in 1988, the principles of the Bamako Initiative were quickly generalized with the adoption of direct payment for care simultaneously applied to curative and preventive acts. The application of the Bamako initiative should then lead to an increase in the use of healthcare facilities, especially at the first level, and improve the health status of the population.

Unfortunately, to this day, the frequency rate of health centers (HC) remains low (Zounmenou, 2017). The reasons are given to explain this state of affairs related to financial and geographic accessibility (Yeo, Kra, \& Koffi, 2016) and then to the quality of reception and care (Atchouta, Doubogan, \& Badou, 2016). With health infrastructure coverage of $93.1 \%$ since 2015 (MS, 2016), without excluding geographic accessibility and poor reception, financial accessibility remains the main cause of the low attendance at health centers (Doubogan, Savi, \& Atchouta, 2017). For poor families, the price of health services is a major barrier to care in particular.

By analyzing the different formulas for financing health expenditure in developing countries, Audibert, Mathonnat, \& de Roodenbeke (2003) stated that the random nature of the disease and, more broadly, the social and economic origin of major health problems militate in favor of a collective coverage of major health expenses, especially in traditional societies. Indeed, in order to improve equity in access to health care for rural populations and to encourage providers of this care to improve the quality and efficiency of services while encouraging the involvement of populations in their management, mutualist type pre-financing systems, with decentralized management can constitute an original alternative, within the reach of rural communities. So, the topic of my article is socio-economic and health determinants of rural households consent to prepay for their health care in N'Dali. I have this topic in order to make household know the importance of pre-financing of their health care. This research work is significant because it helps not only the current generation to know the importance of preserving health care but also the future generation should know it. To do this, this article analyzes the accessibility of rural households to primary health care in northern Benin and more specifically in N'DALI. It attempts to answer the following research questions: What amount(s) are Beninese households, particularly rural households, ready to allocate to pre-finance their health care? What are the likely factors to encourage rural households to pre-finance their health care?

\section{Theory on Willingness to Pay}

Consumer theory is the economic modeling of the behavior of an agent as a 
consumer of goods and services. It is based on the neoclassical individualist paradigm, which postulates that the economic agent always seeks to maximize utility in his purchasing decisions, therefore in the consumption of goods and services. According to this approach, consumer behavior is linked to two determinants: the preferences of individuals on the one hand, and the constraint on their budgets on the other. Studying consumer behavior involves three main steps: identifying individual preferences, that is, understanding how and why agents prefer one good over another; take into account the budgetary constraint weighing on individuals, the combination of preferences and budget constraints then determining consumption choices; identify the combination of goods that agents will choose to maximize their usefulness. Three basic assumptions underlie this theory: individual preferences are complete, that is, they exist for all goods. They are transitive (if $\mathrm{A}$ is preferred to $\mathrm{B}$ and $\mathrm{B}$ to $\mathrm{C}$, then $\mathrm{A}$ is always preferred to C).

The third hypothesis is that of unsatiety, that is to say that agents always prefer to have more than less, whatever the good.

According to consumer theory, willingness to pay is what agents are willing to give up in terms of other consumption opportunities, in order to obtain a combination of goods capable of maximizing their utility taking into account their budgetary constraints. The notion of consent to pay (CAP) is very old and has been developed in several contexts. It can be defined in three main situations:

Public investment will reduce the journey time between two cities.

For each user of the infrastructure, we can express the amount of money he is willing to sacrifice to benefit from the (certain) reduction in travel time. It should be noted immediately that the CAP is akin to the very old notion of "marginal rate of substitution".

This definition of C.AP has been used very often in the assessment of public investment in infrastructure and the environment. We note two essential characteristics: 1) the usefulness of the interviewee is "two-dimensional": it depends on the journey time and the wealth available for consumption and 2) the context is a situation of certainty.

- A willingness to pay can be expressed in a risk context for one-dimensional utility functions.

In this case the CAP is similar to another familiar concept: that of "risk premium". Consider the following lottery:

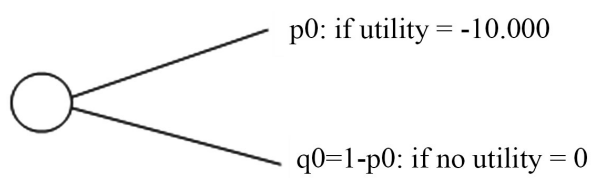

where $\mathrm{p} 0$ is the initial probability of seeing a loss equal to $10,000 \mathrm{~F}$.

In this context, the CAP is defined as the sum of money that someone is ready to invest in order to reduce the initial probability of loss and reduce it from $\mathrm{p} 0$ to 
p0 $-\varepsilon(\varepsilon>0$ and very small).

If we remember that the risk premium is equal to the amount that the individual is ready to pay in order to eliminate the risk (and replace it with his mathematical expectation), we immediately see the link between the two concepts: then that the CAP deals with a marginal change in risk, the risk premium evokes an overall change in risk (in fact its elimination). With regard to lotteries like those described here, the CAP has two important characteristics: 1) the usefulness of the interviewee is "one-dimensional", it depends solely on financial wealth and 2) the context is a risk situation.

\section{- In the domain of health}

The CAP is defined in a framework, which brings together the two previous ones. Indeed:

- the utility function is multi-dimensional: it reflects not only the financial wealth of the individual but also characteristics of his state of health, for example the duration or the quality of his survival;

- the context is that of risk.

In this type of situation, at least three PACs can be defined. Indeed, let's go back to the lottery facing the individual:

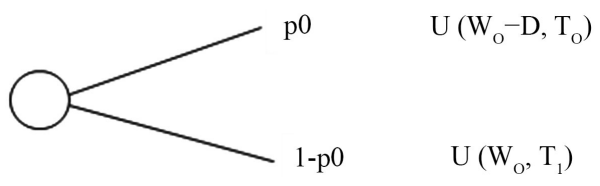

In this lottery the results are represented by a two-dimensional utility where:

- $\mathrm{T}_{0}$ is the survival time in the event of illness and $\mathrm{D}$ represents the financial loss resulting from the illness;

- $\mathrm{T}_{1}$ is the survival time in case of good health.

Faced with this risky situation, we can define the CAP: 1) to reduce p0;2) to increase $\mathrm{T}_{0}$ and 3 ) to reduce $\mathrm{D}$. It is important to note that the most widespread concept of CAP is that corresponding to 1). It was "popularized" by Drèze (1962) and Jones-Lee (1974) as part of their work on the social utility of human life (Eeckhoudt \& Hammit, 2001). However, people could also be interviewed about 2) and 3).

\section{Methodology}

\subsection{Estimate of Willingness to Pay}

The participation of households in the financing of health care poses the problem of the supply and pricing of public health goods and services. Two main theoretical approaches are available to clearly estimate households' willingness to pay for health care:

- the indirect approach: it consists of using data on the use of goods or services to assess consumers' responses;

- the direct approach: it is used to ask individuals how much they are willing to 
pay for the use of a health good or service.

The latter method seeks to construct hypothetical markets for public goods. It is a survey method used to assign monetary values to goods and services for which market prices do not exist or do not reflect the social value of the benefits. One of the major problems linked to the evaluation technique is that for certain reasons, the households surveyed do not clearly answer the questions asked. In this analysis, two variants are used, namely: the closed questionnaire method or the dichotomous choice technique (bidding game) and the open questionnaire method.

The closed questionnaire method consists of starting with a starting amount and asking the respondent if he is ready to pay this amount or not (bidding game). For example "would you be willing to pay X CFA francs for a pre-financing system for your health care?" As for the open questionnaire, the respondent is asked to express their maximum willingness to pay for health care. For example, "What is the maximum amount that you will be willing to pay to participate in a pre-financing health care system?" To elucidate the willingness to pay of rural households for access to health care we use for the needs of our study, the method of contingent analysis at the level of which we only use the dichotomous technique which responds better to the bargaining strategies practiced on the African markets.

\subsection{Modeling of Factors Determining Willingness to Pay}

The information resulting from the technique of dichotomous choices ("bidding-game”) is a set of negative or positive responses resulting from a specific question on discrete values, it is true that the values offered by households within the framework of a community health care pre-financing system are continuous variables. Thus, the dependent value obtained by the dichotomous choice procedure is not the maximum value that the household would be willing to pay for its health care but, rather, the range in which the true value of the willingness to pay would lie. Insofar as there is a risk of violation of the assumptions relating to the error term, the use of the ordinary least squares (OLS) method would not be appropriate for the explanation of the determinants of the willingness to pay contrary to the case where the dependent variable is quantitative. The ordered probit model is therefore the one we will use and whose estimation will be made by the maximum likelihood method.

From the above discussions, consider $V_{m}$ as the maximum amount that household I agree to pay to participate in a community health care pre-financing system. Based on the consumer demand theory we assume that $V_{m}$ is a linearly dependent variable of the explanatory variables. If $X_{m}$ represents the socioeconomic factors of rural households determining $V_{m}$, we have:

$$
V_{m}=+X_{m}+e_{m}
$$

where $\alpha$ and $\beta$ are parameters to be estimated from the model and $e_{m}$ the error term.

Equation (1) cannot be estimated, as long as $V_{m}$ is not observable by the bid- 
ding-game technique. However, based on the responses from the interviews, the area in which $V_{m}$ defines itself is known. Let us also consider $R_{1}, R_{2}, R_{t}$ the $t$ values which share the area of definition of willingness to pay in $t+1$ categories and $Y_{m}$ a categorical variable such as:

$$
Y_{m}=\left\{\begin{array}{c}
1 \text { si } V_{m} \leq R_{1} \\
2 \quad \text { si } R_{1}<V_{m} \leq R_{2} \\
\quad \vdots \\
t+1 \quad \text { si } V_{m} \leq R_{t}
\end{array}\right.
$$

By setting $i=1,2, \cdots, t+1$, it follows, from Equation (1), that:

$Y_{m}=i$ if $R_{i-1}<+x_{m}+e_{m} R_{i}$

Or $R_{i-1}{ }^{-}<X_{m}+e_{m} R_{i}$.

From there, $Y_{m}=i$ if $\left(R_{i-1}--X_{m}\right) /<e_{m} / \delta\left(R_{i^{-}-} X_{m}\right) /$, with the standard error of $e_{m}$.

If we assume that $e_{m}$ follows a standard normal distribution, we have:

$$
\begin{aligned}
P(y=i) & =P\left(R_{i-1}<V_{m} R_{i}\right) \\
& =P\left(u_{i-1}-x_{m}<e_{m} u_{i}-X_{m}\right) \\
& =F\left(u_{i}-x_{m}\right)-F\left(u_{i-1}-x_{m}\right)
\end{aligned}
$$

with $u_{i}=R_{i}$ and $F(-)$ the cumulative function of the standard normal law. Equation (4) is the ordered probit model that will be used to explain the variation in the value of willingness to pay.

Empirically, Equation (1) above can be written in the form:

$$
V_{i}=0+1 X_{i}+e_{i}
$$

with, $V_{i}$ the cumulative function of the reduced normal law and $X_{i}$ the socio-economic and health characteristics of the rural household $i$.

Previous work has shown that the variables representing socio-economic (Kusi et al., 2015; Sanoussi \& Ametoglo, 2019) and health (Cisse \& Sauvain-Dugerdil, 2018) characteristics are likely to determine consent to prepay for health care rural households. These variables are described in Table 1.

The sign of their coefficient makes it possible to assess their effect on the consent to prepay for health care. The sign (+) indicates that the expected effect of the variable concerned on the willingness to pay of households is positive and the sign (-) indicates that the expected effect of the variable concerned on the willingness to pay of households is negative.

\subsection{Study Area and Database}

This study was conducted in northern Benin, in the Borgou department and more specifically in the commune of N'Dali. The latter is limited to the north by the municipalities of Bembèrèkè and Sinendé, to the south by the municipality of Parakou, to the east by the municipality of Nikki and to the west by the municipality of Djougou. With a density of around 12.1 inhabitants per square kilometer and a population of 113,604 inhabitants (INSAE, 2013), the study area covers an area of $3748 \mathrm{~km}^{2}$, which represents $3.33 \%$ of the national territory. 
Table 1. Description of the explanatory variables used in the probit regression model used.

\begin{tabular}{|c|c|c|}
\hline Variables & Description of variables & Expected effects \\
\hline SEX & Category variable representing the gender of the respondent & - \\
\hline AGE & Age of respondent & + \\
\hline SMAT & $\begin{array}{l}\text { Categorial variable representing the marital status of the } \\
\text { respondent }\end{array}$ & - \\
\hline EDUC & $\begin{array}{l}\text { Category variable representing the education level of the } \\
\text { respondent }\end{array}$ & + \\
\hline CHILD & Number of children in the household & + \\
\hline INCOME & Variable representing the level of monthly household income & + \\
\hline STATSAN & Variable representing the household health status & - \\
\hline HOME & $\begin{array}{l}\text { Category variable representing speed in the reception of } \\
\text { Patients }\end{array}$ & + \\
\hline ASSOCOM & $\begin{array}{l}\text { Category variable representing membership in a rural } \\
\text { community action association }\end{array}$ & + \\
\hline PROPERTY & $\begin{array}{l}\text { Categorical variable representing the ownership of the health } \\
\text { center }\end{array}$ & + \\
\hline DOCTOR & $\begin{array}{l}\text { Category variable representing the regular presence of the } \\
\text { doctor at the health center }\end{array}$ & + \\
\hline MSPOMED & $\begin{array}{l}\text { Category variable representing the availability of essential } \\
\text { drugs in the Health Center }\end{array}$ & - \\
\hline TRAD & Tradition of using the local health service & + \\
\hline
\end{tabular}

The data used for the analysis were collected using a structured questionnaire and group interview from one hundred and twenty (120) rural households via household heads. The latter were chosen at random in three (03) districts (Sirarou, Ouenou and Bori) out of the five (05) in N'dali. Observations and triangulation of information were used to ensure the veracity of the information collected.

The data collected relate to the socio-demographic characteristics of rural households (age, sex, marital status, level of education, number of children in the household, membership or not in a rural association d community action, the tradition of using health services and the level of income) and the characteristics specific to the health center (the speed of the reception, the ownership of the health center, the regular presence of the doctor at the center of health and availability of essential drugs at the health center).

\section{Results and Discussion}

\subsection{Socio-Economic and Demographic Characteristics of Households}

Men make up more than half (60.83\%) of the sample size. Women $(39.17 \%)$ are much less represented than men. The proportion of heads of household whose age is between 20 and 50 not included is $72.50 \%$ compared to $27.50 \%$ for those 
whose age is greater than or equal to 50 years. The majority of households are therefore headed by people of working age to provide for the needs of said households. $26.67 \%$ of the respondents never went to school; $37.50 \%$ have primary education; $30.83 \%$ have secondary education and $5 \%$ have higher education. In other words, more than half of the heads of households are educated and therefore are expected, better than the non-educated, to know the importance of using health services in the event of illness.

The married couple more or less the double of Bachelor (divorced and widowed included). These two categories are in respective proportions of $65.33 \%$ and $34.67 \%$. The maximum number of children under 14 in a household is five (05). The proportions of households with 0 and 1 child under the age of 14 are very low. It is $1.67 \%$ for households with 0 children under $14 \%$ and $4.17 \%$ for households with 1 child under 14 . The proportion of households with 2 children under 14 is higher, at $35 \%$.

Household heads working mainly in the agricultural sector are the most numerous and represent more than half of the sample, i.e. $55 \%$. The proportion of heads of household working in the public service is low, it is $6.67 \%$. Traders and artisans are represented by $38.33 \%$ of respondents. It should be noted that few heads of household (28.67\%) belong to a rural community action association or organization.

At least two thirds (2/3) of the respondents have a low monthly income (less than or equal to $25,000 \mathrm{CFA}$ francs). The latter represent $67.67 \%$ of all heads of household surveyed. This income is less than 30,000 FCFA representing the monthly gain according to the SMIG. In other words, more than half of the heads of household in the study area have a monthly income below the average minimum wage in Benin. This is a sign of poverty especially that, the head of household is the nucleus of the household in this capacity, has the power of decision-making and is the first concerned by the expenses related to the structure which he directs. In terms of attendance or use of health services, only $47.67 \%$ of households use health services. This rate is lower than that of bin LUBULA et al. (2017) who, by studying the organization, supply and demand of quality health services in the Democratic Republic of the Congo, found that $92 \%$ of households use a health center in the event of illness in 24 hours.

In this socio-economic context, what is the consent of households to pay for their health care and what are the determining factors for this consent?

\subsection{Consent of Households to Pre-Finance Their Health Care}

Table 2 presents the consent to prepay a household per individual per year for health care.

This table shows that the minimum value per individual per year and the maximum value per individual per year are equal to 7000 FCFA and 14,000 FCFA respectively. More than half of the respondents (51.67\%) are ready to prepay 7000 FCFA to pre-finance their health care and $8.33 \%$ of these respon- 
dents are ready to pay 14,000 FCFA. The average and median amounts of consent to prepay households are respectively equal to 7850 FCFA and 7000 FCFA. If a central trend indicator should be used to indicate the value of households' willingness to prepay for their health care, the median should be used, which is a central trend parameter used to summarize a series of data from a quantitative variable. Based on this indicator, we see that rural households in the commune of N'DALI can agree to pay 7000 FCFA per individual per year to pre-finance their health care. This willingness to pay is very low when we know that there are diseases that alone require much more money.

As the CAP increases, the percentage of heads of household willing to pay decreases. The price that willing to pay varies according to the heads of household. This trend confirms the results of Sigue et al. (2019) in their study of producers' consent to pay for the practices of the components of the microdose technology in the provinces of Kourittenga and Zondoma in Burkina Faso. Thus, they had shown that producers are willing to contribute financially to the adoption of these practices, but that the average amounts of consent varied significantly from one province to another depending on the components.

However, the same observation was observed by Vodouhê and DavoVodouhê (2018) who showed that consumers were ready for a premium varying from 15 to 500 CFA francs per kilogram of organic vegetables in southern Benin. The 7000 FCFA offered per individual per year to pre-finance their health care can be explained by the fact that traditional values are more present in rural areas. In other words, the CAP observed in N'Dali may be due to the fact that populations often resort to traditional medicine in the event of illness. Health centers are generally visited when traditional medicine fails to prove itself or in case of complications and serious illnesses.

Socio-economic and health realities can also explain the amount agreed to pay by the households of this commune. It is therefore important to be interested in the determinants of the CAP for a good understanding.

Table 2. CAP of a household per individual and per year health care.

\begin{tabular}{|c|c|c|}
\hline Value/person/year & Number & Frequency \\
\hline 7000 & 62 & 51.67 \\
\hline 9000 & 30 & 25 \\
\hline 10.000 & 18 & 15 \\
\hline 14.000 & 10 & 8.33 \\
\hline TOTAL & 120 & 100 \\
\hline MINIMUM & & 7000 \\
\hline MAXIMUN & & 14,000 \\
\hline MOYENNE & & 7850 \\
\hline MEDIANE & & 7000 \\
\hline
\end{tabular}

Source: Survey data, 2019. 


\subsection{Determinants of Willingness to Pay of Rural Households}

Estimating Equation (4) allowed us to identify the factors that influence the willingness of rural households to pre-finance health care for future consumption. The thirteen (13) explanatory variables were not taken into account in the estimation of the model. Indeed, after simulations, some variables were found to be non-significant. This is the gender of the respondent (GENDER, household health status (STATSAN), availability of essential drugs (DISPOMED) and marital status (SMAT).

Thus, the following variables were used in the estimation of the model: the age of the respondent (AGE), the education level of the respondent (EDUC), the number of children in the household (CHILD), the level of monthly income of the respondent (INCOME), speed in welcoming patients (HOME), membership of an association or rural community action organization (ASSOCOM), ownership of the health center (CLEANLINESS), presence doctor at the local health center (DOCTOR) and the tradition of using the local health service (TRAD). After the elimination of the non-significant variables, the results of the estimation of the model by the maximum likelihood method are presented in Table 3.

Reading the table tells us that $86.3 \%$ of the variations in the consent of households to prepay for health care is explained by the variables taken into account in the model ( $\mathrm{R}$ squared $(\mathrm{R} 2)=0.863$ ). The student $\mathrm{t}$ statistic which is the test of the significance of the partial regression coefficients makes it possible, through the calculation of the probability linked to each student $t$ statistic, to give the level of significance of the corresponding coefficients. In light of the results recorded in Table 3, all the variables are significant at $5 \%$ because all the probabilities are less than $0.05($ Prob $<0.05)$.

Table 3. Results of estimates from the willingness-to-pay model of rural households to pre-finance their health care.

\begin{tabular}{cccc}
\hline \multirow{2}{*}{ VARIABLES } & \multicolumn{3}{c}{ Variable dependant (CAP) } \\
\cline { 2 - 4 } & Coefficients & t-statistic & Probability \\
\hline AGE & $0.065868^{*}$ & 2.517194 & 0.0257 \\
EDUC & $0.016874^{*}$ & 2.477562 & 0.0277 \\
ENFANT & $0.035677^{* * *}$ & 4.520266 & 0.0006 \\
REVENU & $0.777706^{*}$ & 3.425342 & 0.0377 \\
ACCUEIL & $0.012092^{*}$ & 3.344807 & 0.00358 \\
ASSOCOM & $-0.639963^{* * *}$ & -4.381597 & 0.0007 \\
PROPRETE & $0.011223^{*}$ & -0.225313 & 0.0352 \\
MEDECIN & $0.054949^{*}$ & 1.737298 & 0.0060 \\
TRAD & $0.011314^{*}$ & 2.131417 & 0.0427 \\
R Squared $\left(\mathrm{R}^{2}\right)$ & 0.863050 & & \\
Khi Square & 12.5023 & & \\
\hline
\end{tabular}

Source: Survey data, 2019. 
From the regression results, it appears that the willingness to pay of households is influenced both by the characteristics specific to the respondents and those specific to the local health services.

\section{- Characteristics specific to respondents}

The results in Table 3 show that variables such as the respondent's age (AGE), the respondent's education level (EDUC), the number of children in the household (CHILD), the household income level (INCOME), and the tradition of using the local health service (TRAD) significantly affect at the $5 \%$ threshold the willingness to pay of households to collectively pre-finance their health care. All these variables each display a positive coefficient, therefore of the same sign as its expected effect. Age is positively significant. This variable is therefore relevant in its contribution to explaining the consent to prepay of rural households. The older the respondent, the higher the value of their approval to pay. This is explained by the deterioration in health status with age.

This conclusion invalidates the results of Sigue et al. (2019) that "âgé the older the head of the household, the less likely he is to pay for technology".

The level of education being significant, confirms the results of Racodon et al. (2018) who had shown that physical activity after cardiovascular rehabilitation depends on the academic level of the patients.

The level of household income (INCOME) and the tradition of using local health services (TRAD) are significant and each displayed a positive coefficient; which is consistent with their expected effect. The higher the income, the more the farmer is ready to contribute to his health care. Indeed, "The more the income of a household that uses the local health service increases, the more important it is their consent to pre-finance their health care".

This result confirms the work of Perronnin and Louvel (2018) according to which the level of household income and the social environment are factors that predispose and facilitate the rate of community health care coverage.

The variable (CHILD) representing the number of children in the household displays a coefficient with the same sign as its expected effect; this variable is therefore relevant in explaining the consent to pre-finance rural households. This result also confirms that of Mao: "The larger the household size, the less the landscapes are willing to pay for the medical cooperative". The variable (ASSOCOM) representing the membership of a household in a rural community organization or association displays a sign coefficient contrary to the expected effect. Since its probability (0.0007) is less than (0.05), it is therefore relevant in explaining the approval to prepay of rural households.

\section{Characteristics specific to the local health services}

These are variables such as: the speed with which patients are received (HOME), the cleanliness of the health center (CLEANLINESS) and the presence of a doctor at the local health center (MEDECIN). All these variables each display a coefficient with the same sign (positive) as the expected effect. The variables (HOME) and (CLEANLINESS) are significant and very relevant in ex- 
plaining households' consent to prepay. Reception is the patient's first remedy and therefore very relevant for the use of health care by rural households. It appears that: "The cleaner the health center and the warmer the reception for patients, the more raised the willingness of households to prepay for health care." The variable (DOCTOR) representing the actual or periodic presence of a doctor in the health service is also significant. To involve households in the pre-financing of their health care, it is important that the doctor or nurse is regular at his post.

\section{Conclusion}

The consent of households to pre-finance their health care is not the result of chance but rather of socio-economic and demographic parameters such as the age of the respondent, the level of education of the household, the number of children in the household, membership of a household in a rural community organization or association, tradition of using local health services, speed in welcoming patients, cleanliness of the health center, the actual or periodic presence of a doctor in the health service and especially the level of household income. In short, the determinants of consent to prepay rural households in the commune of N'Dali are the socio-economic factors and the quality of services. Specifically, older respondents are more in favor of consent to prepay than their younger counterparts; similarly, the wealthiest households are in favor of pre-financing than the poor. The value of the willingness to pay which would encourage the adhesion of rural households to the pre-financing health care system is 7000 FCFA. So, social and practical implication is the best way to resolve the problem of pre-finance. According to the research results found I notice that households should enforce their pre-finance for their health care. So, this study is significant for all households. It helps them to understand clearly how to pre-finance.

\section{Conflicts of Interest}

The author declares no conflicts of interest regarding the publication of this paper.

\section{References}

Atchouta, R. A., Doubogan, O., \& Badou, A. (2016). Community Dynamics around the Management of Maternal and Neonatal Health in Weme Environment in Benin: Controversies, Logics and Strategies of the Actors. Journal of Scientific Research of the University of Lomé, 18, 21-39.

Audibert, M., Mathonnat, J., \& de Roodenbeke, E. (2003). Health Financing in Low-Income African and Asian Countries. Karthala Editions.

Bin Lubula, F. M., Chenge, F., Criel, B., Mukalay, A., Luboya, O., \& Tshamba, H. M. (2017). Organization, Supply and Demand of Quality Health Services: 18 Years of Experience in Mutual Health Insurance in South Kivu Province/DR Congo. International Journal of Multidisciplinary and Current Research, 5.

Cisse, S., \& Sauvain-Dugerdil, C. (2018). Geographic Inequalities in the Use of Maternal 
Health Care in Mali: Respective Roles of Individual, Family and Community Characteristics. African Population Studies, 32.

https://doi.org/10.11564/32-3-1230

Doubogan, Y., Savi, A., \& Atchouta, R. (2017). From Public Health Policy to Social Assistance: Mutual Health and Social Equity in the Borgou Department in Benin.

Drèze, J. (1962). The Social Utility of a Human Life. French Journal of Operational Research, 6, 93-118.

Eeckhoudt, L. R., \& Hammit, J. K. (2001). Background Risks and the Value of a Statistical Life. Journal of Risk and Uncertainty, 23, 261-279.

INSAE (2013). Fourth General Census of Population and Housing. Cotonou: National Institute of Statistics and Economic Analysis.

Jones-Lee, M. (1974). The Value of Changes in the Probability of Death or Injury. Journal of Political Economy, 99, 835-849.

Kusi, A., Hansen, K. S., Asante, F. A., \& Enemark, U. (2015). Does the National Health Insurance Scheme Provide Financial Protection to Households in Ghana? BMC Health Services Research, 15, 331. https://doi.org/10.1186/s12913-015-0996-8

MS (2016). Directory of Health Statistics 2015, Department of Programming and Forecasting (p. 163). Cotonou: Ministry of Health.

Perronnin, M., \& Louvel, A. (2018). Complementary Health in 2014: 5\% Not Covered and $12 \%$ among the Poorest $20 \%$.

Racodon, M., Masson, P., \& Peze, T. (2018). Analysis of Social Determinants in Cardiovascular Rehabilitation: Social Inequalities in Health? Physiotherapy, 18, 3-9.

Sanoussi, Y., \& Ametoglo, M. (2019). Magnitude and Determinants of Catastrophic Health Expenditure: Case of Togolese Households. https://doi.org/10.2139/ssrn.3440106

Sigue, H., Labiyi, I. A., Yabi, J. A., \& Biaou, G. (2019). Determinants of the Willingness to Pay (CAP) of Producers for the Practices of the Components of the Microdose Technology in the Provinces of Kourittenga and Zondoma in Burkina Faso. International Journal of Innovation and Applied Studies, 25, 1202-1214.

Vodouhê, G. T., \& DavoVodouhê, S. (2018). Analysis of Consumers' Consent to Pay for Organic Vegetables in Southern Benin. In Ecological and Organic Agriculture Strategies for Viable Continental and National Development in the Context of the African Union's Agenda 2063. Scientific Track Proceedings of the 4th African Organic Conference (pp. 59-64).

Yeo, H., Kra, K. J., \& Koffi, L. F. E. (2016). Transport Infrastructure and Geographic Accessibility of Rural Populations to Urban Health Facilities in the Dense Area of Korhogo (Northern Côte d'Ivoire). Espace Populations Sociétés. http://journals.openedition.org/eps/6331

Zounmenou, A. Y. (2017). Health Insurance and Use of Health Services in Benin (192 p.). Doctoral Dissertation, Godomey: University of Abomey-Calavi. 